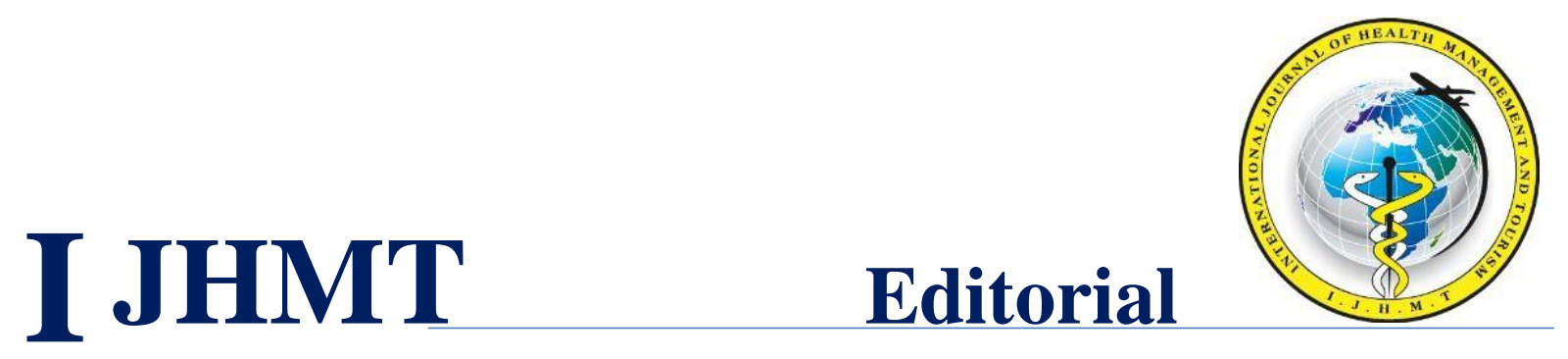

International Journal Of Health Management And Tourism

\title{
THE ROLE OF PATIENT ACTIVATION AND PERSONAL FACTORS ON PATIENT-PHYSICIAN INTERACTION
}

\author{
Fedayi YAĞAR* , Mehveş TARIM** \\ * Research Assistant,Health Management Department,Kahramanmaraş Sütcü İmam University,Turkey \\ fedayiyagar@hotmail.com \\ ORCID Number: 0000-0002-3436-6583 \\ **Prof.Dr., Marmara University, Faculty of Health Sciences \\ mtarim@marmara.edu.tr \\ ORCID Number: 0000-0002-3726-9439 \\ Received: 19.06 .2020 \\ Accepted: 31.08 .2020 \\ Research Article
}

Abstract: This study examines whether the patient-physician interaction level differs according to some personal factors of the patients. 244 patients who came to the university hospital between certain dates to be treated constitute the sample of the study. In the research, a moderately significant positive relationship was found between patient-physician interaction and patient activity and educational status. It was observed that there was a negative and low level relationship between age variable and patient-physician interaction. It has been determined that the individuals with health insurance have better interaction with physicians. No significant difference was found between gender and income status and patient-physician interaction. As a result, this study shows that patient-physician interaction perceptions in healthcare settings vary according to personal patient characteristics. We think that these differences provide important evidence in designing policies to improve health systems at the individual application level.

Key Wordls: Patient Physician Interaction, Patient Activation, Age, Education Level, Health Insurance 


\section{Introduction}

Interaction between the patient and the physician has been classified in several studies (Szasz and Hollender, 1956; Emanuel and Emanuel, 1992; Roter and Hall, 2006). When we look at these classifications, we see that there are two terminal points. We can state the first point as the situation where the doctor is dominant. This point defines "Activity-Passivity Model" (Szasz and Hollender, 1956), "Paternalistic Model" (Emanuel and Emanuel, 1992) and "Paternal Communication" (Roter and Hall, 2006). These approaches focus on information asymmetry between the patient and the physician. The patient plays a more passive role in the decision making process (Budych et al., 2012; Yağar, 2019). On the other extreme point, patient is expected to have a more active role. This point is defined as "Mutual Participation Model" (Szasz and Hollender, 1956), "Interpretive Model" (Emanuel and Emanuel, 1992) and "Consumer Communication" (Roter and Hall, 2006). When we look at the present, it can be said that the patient-centered approach, expressed as the second point, is preferred.

The interaction between the patient and the physician has three main purposes. These; creating a good interpersonal relationship, strengthening the exchange of information and involving patients in the decision making process (Berry, 2007). Particularly, it is very important to ensure the participation of patients in the process. Studies show that patients participating in the process are more satisfied (Jalil et al., 2017; Chen et al., 2008; Boissy et al., 2016) and feel more loyalty (Berry et al., 2008; Kuteyi et al., 2010; Razzaghi and Afshar, 2016). Likewise, it is known that patients who think that they participate in the decisions about their treatment have positive results in their health outcomes (such as reduction of pain felt or control of hemoglobin A1c) (Maly et al., 2004; Hojat et al., 2011; Birkhaur et al., 2017). The investigated studies make it clear why the interaction between the patient and the physician should be good. In this study, it is aimed to examine some variables (personal characteristics and activity levels of patients) that may be related to the level of interaction in order to improve the process. 


\section{Method}

\subsection{Study Population and Sampling}

It is a cross-sectional study. Necessary permissions were obtained for the implementation of the study (27/11/2019-E.49354). The population of the study consists of the patients who came to the university hospital in Kahramanmaraş on 23.12.2019-08.01.2020 for treatment and stated that they have a chronic illness. KSU Training and Research Hospital has been serving since 30.10.2000. In 2013, it moved to its new building in KSÜ Avşar Campus, where 5 polyclinics, 9 dormitory blocks, conference hall and administrative building are located (KSU, 30.08.2020). The total number of beds in the hospital is 516. In terms of health personnel, a total of 690 people are working, including 242 nurses, 238 physicians, 207 other health personnel and 3 midwives (Kahramanmaraş Governorship, 30.08.2020).

The sample of the study consisted of 244 patients who agreed to participate in the study and stated that they were over 18 years old. The fact that the patients answered the questionnaire in the hospital environment can be expressed as an important matter in the study. This situation can affect the objective evaluation. However, evaluations of the patients were taken immediately after receiving the service. With this approach, it was thought that the true opinions of the patients could be revealed better. Likewise, in order to reduce the impact of the hospital environment, the evaluations of patients waiting mostly in the hospital garden were taken into account.

\subsection{Data Collection Instruments}

The scale used in the study consists of three parts. In the first part, there are questions in which the descriptive characteristics of the patients are determined. In this section, patients were asked about their ages, genders, educational levels, health insurance and income status. In the second part, "Patient Activation Measure (PAM)" developed by Hibbard et al. (2004) was used to determine the activity levels of the patients. The Turkish validity and reliability of the 13-question scale (statements were evaluated between $1=$ strongly disagree and $4=$ strongly agree) was made by Koşar and Besen (2019). In our study, the reliability coefficient of the scale (Cronbach Alpha) was found to be 0.864. In the third section, "Patient-Physician 
Interaction Scale (PPI)" developed by Maly et al. (2004) was used to determine the interaction of patients with their physicians. The Turkish validity and reliability of the 10-question scale ((statements were evaluated between $1=$ not sure at all and $5=$ very sure) was made by Akbolat et al. (2016). In our study, the reliability coefficient of the scale (Cronbach Alpha) was found to be 0.882 .

\subsection{Data Analysis}

SPSS 22.0 version was used to analyse the data. Non-parametric tests were used in the study since the data on patient-physician interaction did not show a normal distribution. "MannWhitney U Test" and "Spearman Correlation Test" were used to evaluate the data.

\section{Results}

Data on the descriptive characteristics of the participants are shown in Table 1. It was observed that approximately $59 \%$ of the patients were women, most of them had health insurance $(83.6 \%)$ and the most university graduates $(41.8 \%)$ participated in the study. In addition, it was determined that the average age of the participants was $41,09 \pm 17,18$ and the average income was 2761,00-1947,58 TL (Turkish Lira).

Table 1. Descriptive Characteristics of the Participants

\begin{tabular}{|l|c|c|l|c|c|}
\hline Participants & n & \% & Participants & n & \% \\
\hline Gender & & & Education Level & & \\
Female & 143 & 58,6 & Illiterate & 2 & 0,8 \\
Male & 101 & 41,4 & Literate & 14 & 5,7 \\
Health Insurance & & & Primary school & 17 & 7,0 \\
Yes & 204 & 83,6 & Middle School & 27 & 11,1 \\
No & 39 & 16,0 & High school & 63 & 25,8 \\
& & & University & 102 & 41,8 \\
Regular Sports & & Master and PhD & 19 & 7,8 \\
Yes & & Smoking & & \\
No & 139 & 59,1 & Yes & 156 & 35,0 \\
\hline
\end{tabular}

PPI levels of patients with health insurance $(\mathrm{p}=0,000 ; \mathrm{P}<0,05)$, regular sports $(\mathrm{p}=0,000$; $\mathrm{P}<0,05)$ and non-smoking patients $(\mathrm{p}=0,000 ; \mathrm{P}<0,05)$ were found to be better (Table 2$)$. On the other hand, it was observed that the interaction between the patient and the physician did not differ according to the gender variable. 
Table 2. Examining the Relationship between Gender, Smoking, Sports, Health Assurance and PPI

\begin{tabular}{|c|c|c|c|c|}
\hline & & & PPI & \\
\hline & & Mean Rank & U & $\mathrm{P}$ \\
\hline Gender & Female $(n=143)$ & 119,49 & 6814,000 & 0,785 \\
\hline & Male $(n=101)$ & 121,97 & & \\
\hline Health Insurance & Yes $(n=200)$ & 127,26 & 2449,000 & $0,000 *$ \\
\hline & No $(n=39)$ & 87,79 & & \\
\hline Regular Sports & Yes $(n=93)$ & 151,54 & 3204,500 & $0,000 *$ \\
\hline & No $(n=139)$ & 93,05 & & \\
\hline Smoking & Yes $(n=84)$ & 89,11 & 3915,500 & $0,000 *$ \\
\hline & No $(n=156)$ & 137,40 & & \\
\hline
\end{tabular}

Table 3 shows that there is a moderately significant positive relationship between patientphysician interaction and patient activity $(\mathrm{r}=0.579 ; \mathrm{p}<0.01)$ and educational level $(\mathrm{r}=0.418$; $\mathrm{p}$ <0.01). Likewise, there was a negative and low-level relationship between age variable and PPI $(r=-0,156 ; p<0.05)$.

Table 3. Examining the Relationship between PAM, Income Status, Education Level, Age and PPI

\begin{tabular}{|c|c|c|c|c|c|}
\hline & & PAM & $\begin{array}{c}\text { Income } \\
\text { Status }\end{array}$ & $\begin{array}{c}\text { Education } \\
\text { Level }\end{array}$ & Age \\
\hline \multirow{3}{*}{ PPI } & Pearson "r" & $0,579 * *$ & 0,097 & $0,418 * *$ & $-0,156^{*}$ \\
\cline { 2 - 6 } & $\mathrm{p}$ & 0,000 & 0,221 & 0,000 & 0,017 \\
\cline { 2 - 6 } & $\mathrm{N}$ & 240 & 161 & 240 & 233 \\
\hline \multirow{2}{*}{$* * \mathrm{p}<0,01 ; * \mathrm{p}<0,05$} & \multicolumn{5}{|l}{} \\
\hline
\end{tabular}

\section{Discussion}

This study examined the relationship between the patient's personal characteristics and activity levels and the patient-physician interaction level. The findings reveal that the level of interaction between the patient and the physician differs according to patient perceptions.

Individuals who think that they have the knowledge, skills and confidence in healthcare are expected to take more actions that improve their health. This shows that individuals have high levels of activity (Mosen et al., 2007). This level is desired especially in chronic diseases. Researches on the subject show that it positively affects both health outcomes (Parchman et al., 2010; Kim et al., 2016) and patient-physician relations (Alexander et al., 2012; Alegria et 
al., 2009). In our research, a result supporting the literature was found. A positive correlation was found between patient activity and PPI $(\mathrm{r}=0.579 ; \mathrm{p}<0.01)$.

It is known that elderly patients with high level of relationship with the physician are more stable in the treatment process (Maly et al., 2004). On the other hand, studies show that the communication of individuals with the physician decreases as they get older (Belcher et al., 2006; Liang et al., 2013). In our study, it was found that there is a low level of significant relationship between the age variable and PPI $(r=-0.166 ; p<0.05)$. Although the level of relationship we obtained is low, it seems to support the literature.

In our study, it was determined that the individuals with health insurance were higher in relation to the physician, while the income status and gender variables were not related to PPI. Research conducted by DeVoe et al. (2009) supports our conclusion about health insurance. In this study, it was emphasized that the interaction of individuals without insurance with physicians is not good. In the same study, the gender variable was also taken into consideration and it was stated that men communicate better than women. In the study conducted by Jensen et al. (2010), the income status variable was taken into consideration and it was stated that PPI levels of high income individuals are better.

In a study conducted in 31 countries by Aelbrecht et al. (2019) on approximately fifty thousand participants, it was emphasized that the level of PPI increases as the level of education increases. Likewise, in a study conducted by Lu and Zhang (2019), it was observed that individuals with high education level participated more in the decision making process with the physician. In our research, a similar result was found and a positive significant relationship was found between the education level and PPI.

In summary, we observed that young individuals, individuals with higher education levels, individuals with health insurance and individuals with high patient activity levels interact better with physicians. From the perspective of the patient, with the short-term trainings to be given, both the patients' level of activity can be increased and the elderly individuals can be better interacted. Researches provide evidence that education can play an important role at this point (Worrall et al., 1998; Guzman and Dino, 2020; Williams et al., 2005; Remmers et 
al., 2009). On the other hand, the role of physicians in this interaction should not be forgotten. In this process, physicians should pay attention to the patient's opinions, try to communicate better and be able to empathize.

This study includes the patients who come to Kahramanmaraş Sütçü İmam University Training and Research Hospital for treatment between certain dates. Therefore, the results of the study reflect the views of the patients who applied to the hospital, and it is unlikely that these findings will be generalized to all patients. However, it can be said that the results obtained can provide important clues in revealing the relationship between variables. Finally, some suggestions have been made for future research. First, a larger sample can be studied to increase the generalization of the results. Second, a model can be created that takes into account the different personal characteristics of the patients. Third, studies that take patient and physician evaluations into account can be conducted to provide a more holistic perspective.

\section{References}

Aelbrecht, K., Hanssens, L., Detollenaere, J., Willems, S., Deveugele, M. and Pype, P. (2019). Determinants of physician-patient communication: The role of language, education and ethnicity. Patient Education and Counseling, 102(4), 776-781. https://doi.org/10.1016/j.pec.2018.11.006

Akbolat, M. (2016). Sağlık okuryazarlığı hasta-hekim ilişkisini etkiler mi?: Sakarya ilinde bir araştırma. TAF Preventive Medicine Bulletin, 15(4), 354-362. https://www.doi.org/10.5455/pmb.1-1455008901

Alegría, M., Sribney, W., Perez, D., Laderman, M. and Keefe, K. (2009). The role of patient activation on patient-provider communication and quality of care for US and foreign born Latino patients. Journal of General Internal Medicine, 24(3), 534-541. https://www.doi.org/10.1007/s11606-009-1074-x 
Alexander, J. A., Hearld, L. R., Mittler, J. N. and Harvey, J. (2012). Patient-physician role relationships and patient activation among individuals with chronic illness. Health Services Research, 47(3), 1201-1223. doi:10.1111/j.1475-6773.2011.01354.x

Belcher, V. N., Fried, T. R., Agostini, J. V. and Tinetti, M. E. (2006). Views of older adults on patient participation in medication-related decision making. Journal of General Internal Medicine, 21(4), 298-303. doi:10.1111/j.1525-1497.2006.00329.x

Berry, L. L., Parish, J. T., Janakiraman, R., Ogburn-Russell, L., Couchman, G. R., Rayburn, W. L. and Grisel, J. (2008). Patients' commitment to their primary physician and why it matters. The Annals of Family Medicine, 6(1), 6-13. doi:10.1370/afm.757

Berry, D. (2007). Health communication: Theory and practice. Typeset by Refine Catch Ltd, Bungay.

Birkhäuer, J., Gaab, J., Kossowsky, J., Hasler, S., Krummenacher, P., Werner, C. and Gerger, H. (2017). Trust in the health care professional and health outcome: a meta-analysis. Plos One, 12(2), 1-13. doi:10.1371/journal.pone.0170988

Boissy, A., Windover, A. K., Bokar, D., Karafa, M., Neuendorf, K., Frankel, R. M. and Rothberg, M. B. (2016). Communication skills training for physicians improves patient satisfaction. Journal of General Internal Medicine, 31(7), 755-761. doi:10.1007/s11606-016$\underline{3597-2}$

Budych, K., Helms, T. M. and Schultz, C. (2012). How do patients with rare diseases experience the medical encounter? Exploring role behavior and its impact on patientphysician interaction. Health Policy, 105(2-3), 154-164. doi:10.1016/j.healthpol.2012.02.018

Chen, J. Y., Tao, M. L., Tisnado, D., Malin, J., Ko, C., Timmer, M. and Kahn, K. L. (2008). Impact of physician-patient discussions on patient satisfaction. Medical Care, 46(11), 11571162. doi:10.1097/MLR.0b013e31817924bc

DeVoe, J. E., Wallace, L. S. and Fryer, G. E. (2009). Measuring patients' perceptions of communication with healthcare providers: do differences in demographic and socioeconomic 
characteristics matter?. Health Expectations, 12(1), 70-80. $\quad \underline{\text { doi:10.1111/j.1369- }}$ $\underline{7625.2008 .00516 . x}$

Emanuel, E. J. and Emanuel, L. L. (1992). Four models of the physician-patient relationship. JAMA, 267(16), 2221-2226. doi:10.1001/jama.1992.03480160079038

Guzman, A.B. and Dino, M.J.S. (2020). Examining the role of Filipino elderly attitudes toward computer and internet on their behavioral intention for telehealth participation, Educational Gerontology, 46(3), 140-149. doi:10.1080/03601277.2020.1715589

Hibbard, J.H., Mahoney, E.R., Stockard, J., Tusler, M. (2005). Development and testing of a short form of the patient activation measure. Health Services Research, 40(6), 1918-30. doi:10.1111/j.1475-6773.2005.00438.x

Hojat, M., Louis, D. Z., Markham, F. W., Wender, R., Rabinowitz, C. and Gonnella, J. S. (2011). Physicians' empathy and clinical outcomes for diabetic patients. Academic Medicine, 86(3), 359-364. doi:10.1097/ACM.0b013e3182086fe1

Jalil, A., Zakar, R., Zakar, M. Z. and Fischer, F. (2017). Patient satisfaction with doctorpatient interactions: a mixed methods study among diabetes mellitus patients in Pakistan. BMC Health Services Research, 17(1), 1-13. doi:10.1186/s12913-017-2094-6

Jensen, J. D., King, A. J., Guntzviller, L. M. and Davis, L. A. (2010). Patient-provider communication and low-income adults: Age, race, literacy, and optimism predict communication satisfaction. Patient Education and Counseling, 79(1), 30-35. doi:10.1016/j.pec.2009.09.041

Kahramanmaraş Governorship. (2020). Distribution of health institutions, bed availability and number of health personnel. www.kahramanmaras.gov.tr/saglik, (Date of access: 30.08.2020).

Kosar, C. and Besen, D.B. (2019). Adaptation of a patient activation measure (PAM) into Turkish: reliability and validity test. African Health Sciences, 19(1), 1811-20. $\underline{\text { doi:10.4314/ahs. v19i1.58 }}$ 
KSU. (2020). Presentation of the institution. hastane.ksu.edu.tr/Default.aspx?SId=18876, (Access Date: 30.08.2020)

Kuteyi, E. A., Bello, I. S., Olaleye, T. M., Ayeni, I. O. and Amedi, M. I. (2010). Determinants of patient satisfaction with physician interaction: a cross-sectional survey at the Obafemi Awolowo University Health Centre, Ile-Ife, Nigeria. South African Family Practice, 52(6), 557-562. doi:10.1080/20786204.2010.10874047

Liang, C. Y., Wang, K. Y., Hwang, S. J., Lin, K. C. and Pan, H. H. (2013). Factors affecting the physician-patient relationship of older veterans with inadequate health literacy: an observational study. Br. J. Gen. Pract., 63(610), 354-360. doi:10.3399/bjgp13X667222

Lu, X. and Zhang, R. (2019). Impact of physician-patient communication in online health communities on patient compliance: cross-sectional questionnaire study. Journal of Medical Internet Research, 21(5), 1-18. doi:10.2196/12891

Maly, R. C. (1998). Perceived efficacy in patient-physician interactions (PEPPI): validation of an instrument in older persons. Journal of the American Geriatrics Society, 46(7), 889-894. doi:10.1111/j.1532-5415.1998.tb02725.x

Maly, R. C., Leake, B. and Silliman, R. A. (2004). Breast cancer treatment in older women: impact of the patient-physician interaction. Journal of the American Geriatrics Society, 52(7), 1138-1145. doi:10.1111/j.1532-5415.2004.52312.x

Mosen, D. M., Schmittdiel, J., Hibbard, J., Sobel, D., Remmers, C. and Bellows, J. (2007). Is patient activation associated with outcomes of care for adults with chronic conditions?. The Journal of Ambulatory Care Management, 30(1), 21-29. doi:10.1097/00004479-200701000$\underline{00005}$

Parchman, M. L., Zeber, J. E. and Palmer, R. F. (2010). Participatory decision making, patient activation, medication adherence, and intermediate clinical outcomes in type 2 diabetes: a STARNet study. The Annals of Family Medicine, 8(5), 410-417. doi:10.1370/afm.1161 
Razzaghi, M. R. and Afshar, L. (2016). A conceptual model of physician-patient relationships: a qualitative study. Journal of Medical Ethics and History of Medicine, 9(14), $1-7$.

Remmers, C., Hibbard, J., Mosen, D. M., Wagenfield, M., Hoye, R. E. and Jones, C. (2009). Is patient activation associated with future health outcomes and healthcare utilization among patients with diabetes?. The Journal of Ambulatory Care Management, 32(4), 320-327. doi:10.1097/JAC.0b013e3181ba6e77

Roter, D.L. and Hall, J.A. (2006). Doctors Talking with Patients / Patients Talking with Doctors Improving Communication In Medical Visits. Second Edition. Greenwood Publishing, Connecticut.

Szasz, T. S. and Hollender, M. H. (1956). A contribution to the philosophy of medicine: the basic models of the doctor-patient relationship. AMA Archives of Internal Medicine, 97(5), 585-592. doi:10.1001/archinte.1956.00250230079008

Williams, G. C., McGregor, H., Zeldman, A., Freedman, Z. R., Deci, E. L. and Elder, D. (2005). Promoting glycemic control through diabetes self-management: evaluating a patient activation intervention. Patient Education and Counseling, 56(1), 28-34. $\underline{\text { doi:10.1016/j.pec.2003.11.008 }}$

Worrall, L., Hickson, L., Barnett, H. and Yiu, E. (1998). An evaluation of the keep on talking program for maintaining communication skills into old age. Educational Gerontology, 24(2), 129-140. doi:10.1080/0360127980240203

Yağar, F. 2019. What are the factors affecting the interaction between the patient and the physician?. International Journal of Health Management and Tourism, 4(2), 129-139. $\underline{\text { doi:10.31201/20ijhmt.595677 }}$ 